This is the final peer-reviewed accepted manuscript of:

Verzulli, R., Fiorentini, G., Lippi Bruni, M., \& Ugolini, C. (2017). Price changes in regulated healthcare markets: do public hospitals respond and how?. Health economics, 26(11), 1429-1446.

The final published version is available online at:

https://doi.org/10.1002/hec.3435

Rights / License:

The terms and conditions for the reuse of this version of the manuscript are specified in the publishing policy. For all terms of use and more information see the publisher's website.

This item was downloaded from IRIS Università di Bologna (https://cris.unibo.it/)

When citing, please refer to the published version. 


\title{
PRICE CHANGES IN REGULATED HEALTHCARE MARKETS: DO PUBLIC HOSPITALS RESPOND AND HOW?
}

\author{
ROSSELLA VERZULLI*, GIANLUCA FIORENTINI, MATTEO LIPPI BRUNI and CRISTINA UGOLINI \\ Department of Economics, University of Bologna, Bologna, Italy
}

\begin{abstract}
This paper examines the behaviour of public hospitals in response to the average payment incentives created by price changes for patients classified in different diagnosis-related groups (DRGs). Using panel data on public hospitals located within the Italian region of Emilia-Romagna, we test whether a 1-year increase in DRG prices induced public hospitals to increase their volume of activity and whether a potential response is associated with changes in waiting times and/or length of stay. We find that public hospitals reacted to the policy change by increasing the number of patients with surgical treatments. This effect was smaller in the 2 years after the policy change than in later years, and for providers with a lower excess capacity in the pre-policy period, whereas it did not vary significantly across hospitals according to their degree of financial and administrative autonomy. For patients with medical DRGs, instead, there appeared to be no effect on inpatient volumes. Our estimates also suggest that an increase in DRG prices had no impact on the proportion of patients waiting more than 6 months. Finally, we find no evidence of a significant effect on patients' average length of stay. Copyright (C) 2016 John Wiley \& Sons, Ltd.
\end{abstract}

JEL Classification: Analysis of health care markets (I11); Health production (I12); Government policy, regulation, public

KEY WORDS: DRG prices; average payment incentives; hospital behaviour

\section{INTRODUCTION}

Assessing whether and how financial incentives affect the behaviour of healthcare suppliers is a key factor for implementing welfare-enhancing policies. Information asymmetries and potentially diverging objectives between financing institutions and providers generate considerable challenges for the design of optimal reimbursement schemes, and a substantial body of research has analysed the implications of different payment mechanisms for healthcare delivery (Chalkley and Malcomson, 2000, 2012; McGuire, 2000).

In the hospital sector, a large stream of literature has focused on the switch from a retrospective cost-based reimbursement scheme to a prospective payment system (PPS). Under cost-based reimbursement, hospitals are paid according to their actual costs, thereby receiving little incentive to be efficient. By contrast, under PPS, hospitals receive a fixed price per case treated, with the amount varying according to the diagnostic category (DRG) assigned to each patient. Several studies have investigated the impact of eliminating marginal reimbursements during the transition to PPS. ${ }^{1}$ Most of them have found that a (neutral revenue) shift encourages hospital efficiency, although with potential unintended consequences on patient outcomes (Dranove, 2012).

\footnotetext{
*Correspondence to: Department of Economics, Piazza Scaravilli 2, Bologna 20146, Italy. E-mail: rossella.verzulli@unibo.it

${ }^{1}$ For a given DRG, hospitals do not receive additional payments when they face a cost per case higher than the PPS price.
} 
Yet relatively little attention has been drawn to the response of hospitals to changes in average reimbursement levels (DRG prices).

Theoretical work predicts that, under PPS, hospitals are incentivised to attract more patients in response to an increase in DRG tariffs (e.g. Hodgkin and McGuire, 1994). This issue is attracting growing interest, as the transition to PPS has been completely phased in, and subsequent adjustments of DRG prices may constitute an important lever to steer providers' decisions. Some evidence is available on the impact of changes in average payment levels on the behaviour of hospitals operating in market-oriented institutional settings (e.g. Gilman, 2000; Dafny, 2005; Lindrooth et al., 2007; He and Mellor, 2012). However, very little is known on the effect in national healthcare systems, where the response of public hospitals to DRG price changes can hardly be determined a priori (Januleviciute et al., 2015). On the one hand, an increase in average payments may affect hospital activity when DRG tariffs are used to allocate public funding, especially if public hospitals are required to meet break-even conditions and are allowed to use financial surpluses for investment in patient care. Hospitals' responsiveness to economic incentives is also expected to increase with the financial pressure exerted by restraints in public finances and by restrictive rules for bailing out hospital deficits. ${ }^{2}$ On the other hand, public hospitals may be less responsive to economic incentives than private providers because of differences in their objective function that may arise from public accountability and social obligations. ${ }^{3}$ Moreover, in national healthcare systems, where hospitals are mainly government-owned and private providers are often allowed to play only a residual role, the public sector exerts a deep influence on the supply of hospital care. Inter-hospital competition is typically mitigated by planning requirements based on health needs and financial sustainability, and hospitals are ultimately accountable to the same principal, that is, the central government with its regional bodies. In such a context, it is particularly interesting to assess how reactive public hospitals are to the financial component of their objective function, as their response is net of the potential effects of strong competitive pressures. These effects may instead influence hospital response in other health systems that rely on private providers relatively more (such as in those based on private and social insurance) and whose evidence cannot be straightforwardly extended to national healthcare systems.

In this paper, we thus aim at addressing the empirical question of whether and how public hospitals react to changes in average payment incentives and to what extent the evidence can be passed on across different institutional settings. To do this, we examine a policy change implemented in the Italian region EmiliaRomagna, whereby the prices of a subset of DRGs were increased in 2007 by $6 \%$ on average, whereas they were kept constant for the remaining DRGs from 2005 to 2010. We exploit this policy change to investigate the implications of an increase in average payment levels on the performance of public hospitals in EmiliaRomagna as measured by different indicators, including volumes of activity, waiting times and length of stay. Specifically, we assess whether increasing DRG prices induced public hospitals to expand the number of patients in the affected DRGs relative to the unaffected ones, and we evaluate the impact on the proportion of patients waiting more than 6 months and on patients' average length of stay.

Our analysis exploits a one-time shock in DRG prices to test for differences between short-run and mediumrun effects, an important but often neglected issue. Moreover, we investigate a policy change encompassing a wide range of conditions, while some earlier research (e.g. Allen et al., 2016) covered a more narrow set of procedures. Further, we consider a richer set of performance indicators than those previously examined for National Health Service (NHS) systems and assess whether the policy had a greater impact on hospitals

${ }^{2}$ For a discussion on the role of soft budget constraints in the Italian public health sector, see Barbetta et al. (2007) and Bordignon and Turati (2009).

${ }^{3}$ Clark and Milcent (2011) find a significant gap in public-private employment levels in the French hospital sector associated to depressed local labour markets. The results suggest that public hospitals employment and local unemployment rates are positively correlated only in left-wing municipalities, with a larger correlation for tighter electoral races. Bloom et al. (2015) show that hospital density in the UK is substantially higher in politically marginal constituencies, a feature attributed to the higher political costs of hospital closures. These pieces of evidence point to a significant influence of political factors on management practices in public hospitals. 
enjoying a higher degree of autonomy over financial and organisational matters. ${ }^{4}$ Finally, we examine whether the price change affected hospitals with larger unused capacity more.

Our findings indicate that, on average, hospitals responded to an increase in tariffs by raising the number of surgical (elective) treatments for the affected DRGs relative to the unaffected ones. This effect was smaller in the 2 years immediately after the price change and increased in the next 2 years; a $1 \%$ increase in the price of surgical DRGs raised the number of patients in affected DRGs by $1.7 \%$ and $4 \%$ in the short-run and mediumrun post-policy periods, respectively. Moreover, providers with higher excess capacity before policy implementation displayed a larger response, whereas we do not find differences in hospitals' response depending on their degree of administrative and financial autonomy. An increase in tariffs had no impact on the volumes of (elective) patients treated for medical DRGs. As for patients waiting more than 6 months, we find little evidence of a price effect, and no support emerges for the hypothesis that hospitals responded by altering patients' average length of stay.

\section{RELATED LITERATURE}

The first studies to analyse the hospitals' response to changes in average payments (price changes) at the diagnosis level utilise data covering the period of transition to PPS and thus face the difficulty of disentangling the impact of simultaneous changes in average and marginal payment incentives (e.g. Newhouse, 1989; Cutler, 1995; Gilman, 2000). Dafny (2005) circumvents this problem by exploring the response of hospitals to changes in DRG prices in the post-PPS era. The contribution focuses on the behaviour of US Medicare programme hospitals in response to a price change generated by the elimination of the age criterion in the description of DRG pairs and shows a small impact in terms of volume of activity and intensity or quality of care. In more recent years, some studies have addressed DRG-specific responses of hospitals to price changes, mostly referring to the US context and examining the effect of reimbursement cuts by Medicare. Lindrooth et al. (2007) find that hospitals with high-share Medicare patients decreased treatment intensity more than others, as they experienced larger reductions in average reimbursements. Moreover, the reduction was larger for the more generously reimbursed diseases and for patients requiring higher intensity. Other papers explore the impact of reductions in Medicare payments on health outcomes. While some of them find no adverse effects in the short-run (Seshamani et al., 2006), others highlight higher mortality rates in the long-run for hospitals facing larger payment cuts (Wu and Shen, 2014). Outside the USA, Liang (2015) estimates the substitution and complementarity across DRGs with different profitability for hospitals under a DRG-based payment scheme in Taiwan. The evidence supports both the hypothesis of positive own-price effects, with an increase in the share of patients for the more profitable DRGs, and of negative cross-price effects.

Whereas the aforementioned studies have focused on hospital behaviour within competitive markets, a more limited stream of research has analysed hospital response to DRG price changes in national healthcare systems. To the best of our knowledge, only two contributions explicitly address this issue. Allen et al. (2016) analyse the Best Practice Tariffs reform in England, whereby the prices of a small group of interventions were set proactively to reflect the costs of delivering best practices instead of reactively on the basis of average hospital costs. The results suggest that the policy increased the rate of day cases for the targeted procedures with no detrimental effect in terms of mortality and readmission rates. Finally, Januleviciute et al. (2015) analyse hospital response following continuous refinements in DRG prices within the Norwegian healthcare system. Their findings indicate that, on average, an increase in DRG prices by $10 \%$ increased the number of emergency and elective patients with medical treatments by about $0.8 \%$ and $1.3 \%$, respectively, whereas there is little evidence that hospitals adjusted the volume of surgical activity. Interestingly, these findings partly diverge from

\footnotetext{
${ }^{4}$ While the effects on hospital performance from granting more financial and operational freedoms have received some attention in the UK (Marini et al., 2008; Verzulli et al., 2011; Allen et al., 2012), this issue is still relatively unexplored in the Italian context.
} 
ours as we highlight a significant impact of price changes on surgical procedures for elective patients, but no effects emerge either for elective medical DRGs or for non-elective procedures. Differences in the design of the policy intervention, in the regulatory arrangements and in providers' characteristics may explain part of the heterogeneity in the empirical results. Still, such mixed evidence confirms the importance of improving our understanding of the consequences of DRG price changes in NHS systems.

\section{DATA}

We use data on inpatient discharges at public hospitals sited in Italy's region of Emilia-Romagna. ${ }^{5}$ The Italian NHS provides universal and comprehensive care financed by general taxation, where provision of healthcare services falls mainly under the responsibility of regional governments, and patients can freely choose hospital care from any publicly financed provider. The largest hospitals (Aziende Ospedaliere, AOs) are granted the status of autonomous Trusts and are extensively financed through the use of a DRG-based PPS. The remaining hospitals are managed by the Aziende Sanitarie Locali (ASLs), public enterprises mostly funded via a capitated budget and responsible for the delivery of care to their catchment population. ${ }^{6}$ Once the resources are assigned to each ASL, DRG prices are used by ASLs to quantify the activity of hospitals under their direct control and thus contribute to setting their separate budgets. Such arrangements point towards a relevant role of DRG prices in allocating the available resources across all public hospitals (Cappellari et al., 2016).

Our dataset combines patient records and DRG prices between 2005 and 2010. Patients data are drawn from the administrative hospital discharge dataset (Schede di Dimissione Ospedaliera, SDO). The SDO dataset contains patient-level information, including type of admission (elective or non-elective), booking date, date of admission and discharge, primary diagnosis (DRG), patient's municipality of residence and a hospital identifier. The sample used for the main analysis consists of all acute patients residing in the hospital's catchment area who received an elective inpatient treatment between 2005 and 2010. Then, we matched our sample of patient-level information with the price tariffs set by the Regional Government for all the DRGs in use between 2005 and 2010. Such prices were set by the regional government to fund Emilia-Romagna hospitals for the treatments they provided to residents. Hospital reimbursements for treating patients residing outside the region are paid on the basis of national tariffs and, therefore, this latter group of patients is not included in our analysis, which is confined to those cases whose DRG prices were subject to regional regulation. ${ }^{7}$ The data were then aggregated at the hospital-DRG-year level, leaving us with a final sample of 14516 observations. The number of hospitals covered in the analysis is 14, whereas the total number of DRGs is 279 , divided between 164 affected DRGs and 115 unaffected DRGs. ${ }^{8}$

\subsection{Diagnosis-related group prices}

Table I displays the summary statistics for the prices of medical and surgical DRGs (panel A and B, respectively), distinguishing between the affected DRGs (both pre-shock and post-shock) and the unaffected ones. Average values are plotted in Figure 1 showing that prices for affected DRGs increased by an average

\footnotetext{
${ }^{5}$ This region is located in the North East of Italy and has a total population of nearly 4.5 million people in 2015.

${ }^{6}$ The capitation formula depends on the population size, weighted by age-specific hospital utilisation rates and risk-adjusted mortality rates, to account (at least partially) for the healthcare needs of the population enrolled in each ASL.

${ }^{7}$ Our final sample covers all patients treated in the same area where they are enrolled, representing more than $80 \%$ of total cases. We excluded highly complex procedures, such as organ transplants and treatments for patients with major burns and trauma conditions, as they are funded on the basis of block contracts. We also excluded patients treated in community hospitals, because these (smaller) facilities deal only with low complexity cases, and are subject to a funding scheme that does not apply the DRG prices used to reimburse the larger providers.

${ }^{8}$ Because not all DRGs were treated by each hospital during each year between 2005 and 2010, the total number of observations included in our dataset is lower than 14 hospitals $\times 279$ DRGs $\times 6$ years.
} 
Table I. Descriptive statistics for DRG prices (Euro)

\begin{tabular}{|c|c|c|c|c|c|}
\hline & No. of DRGs & Mean & SD & Min & Max \\
\hline \multicolumn{6}{|l|}{ Panel A: Medical DRGs } \\
\hline \multicolumn{6}{|l|}{ Affected DRGs } \\
\hline Pre-shock & 114 & 1978.32 & 830.95 & 687.92 & 5195.48 \\
\hline Post-shock & 114 & 2088.86 & 853.58 & 715.44 & 5403.30 \\
\hline \multicolumn{6}{|l|}{ Non-affected DRGs } \\
\hline Pre-shock and post-shock & 59 & 2479.40 & 1035.09 & 440.79 & 5283.31 \\
\hline \multicolumn{6}{|l|}{ Panel B: Surgical DRGs } \\
\hline \multicolumn{6}{|l|}{ Affected DRGs } \\
\hline Pre-shock & 50 & 2324.82 & 1201.95 & 570.55 & 5906.47 \\
\hline Post-shock & 50 & 2446.25 & 1237.51 & 593.37 & 6142.73 \\
\hline \multicolumn{6}{|l|}{ Non-affected DRGs } \\
\hline Pre-shock and post-shock & 56 & 3407.71 & 2222.62 & 787.59 & 10146.54 \\
\hline
\end{tabular}

DRGs, diagnosis-related groups.

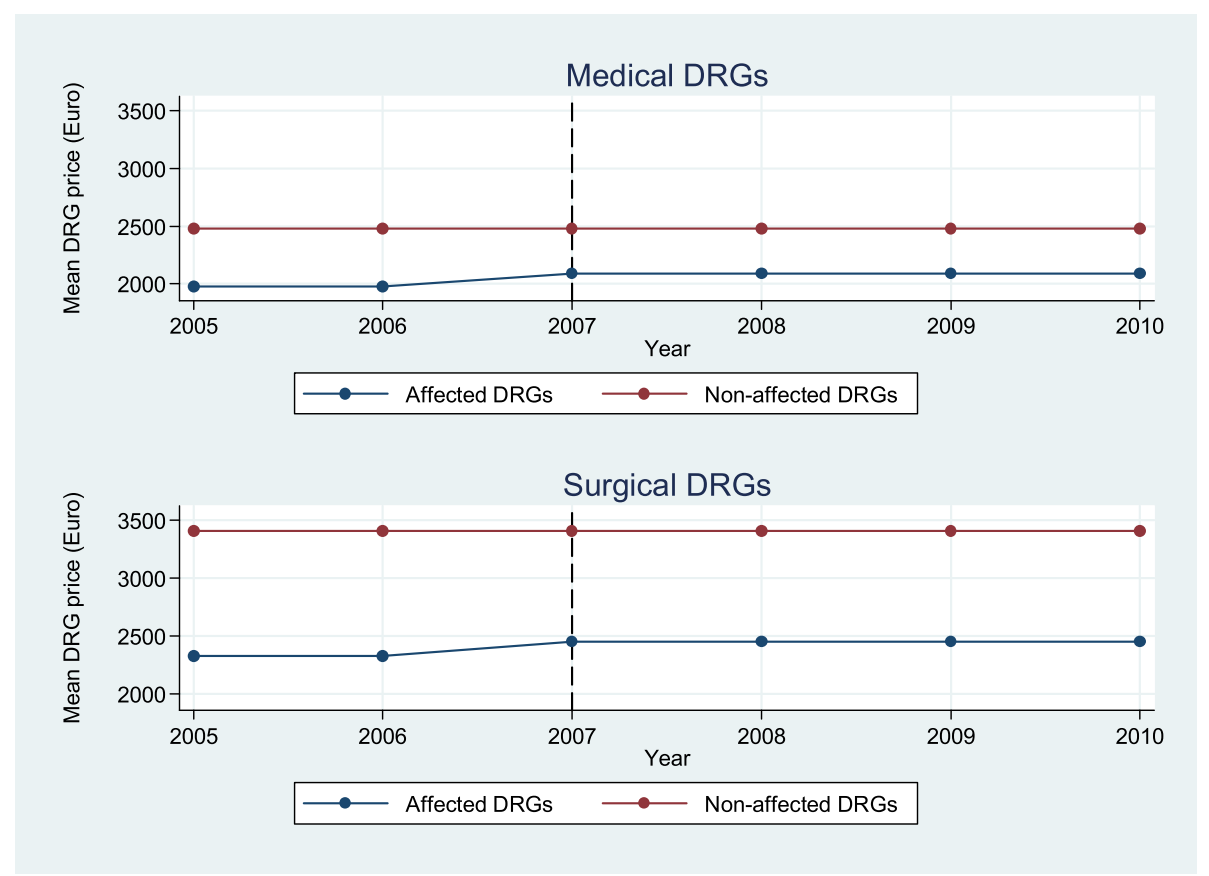

Figure 1. Mean prices of affected and non-affected diagnosis-related groups (DRGs), by year and type of DRG

of EUR 111 for medical DRGs and of EUR 121 for surgical DRGs. The average price is always lower for affected DRGs than for the unaffected ones, suggesting that the DRGs targeted by the policy change covered less complex procedures on average.

\subsection{Dependent variables}

Figure 2 plots the total number of yearly inpatient discharges by type of conditions and by treatment status between 2005 and 2010. For both medical and surgical treatments, the volume of activity is always higher for the affected DRGs than for the unaffected ones. We observe broadly parallel trends for both medical and surgical treatments between the affected and unaffected DRGs in the pre-policy years. Between 2007 and 2010, there was a small decline in the volume of medical treatments for patients in the group of affected DRGs 


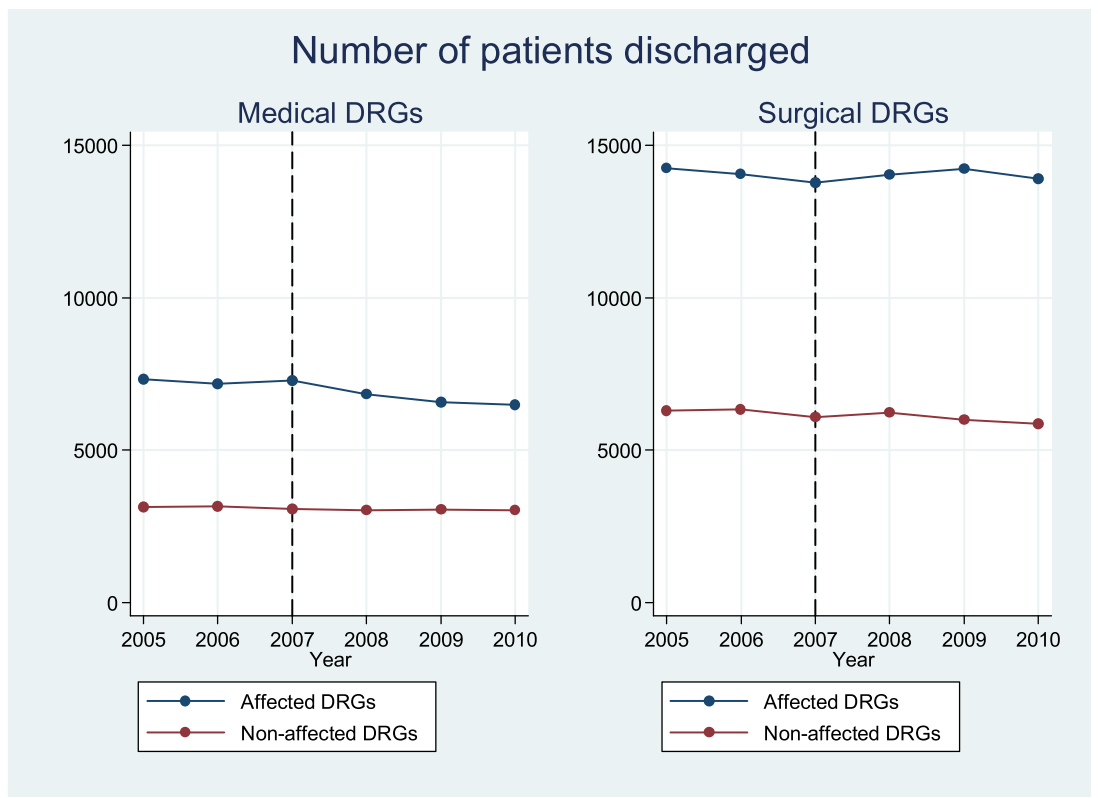

Figure 2. Number of elective inpatient discharges at all hospitals, by year and type of diagnosis-related group (DRG)

and no substantial change for patients in the unaffected DRGs. Conversely, we observe an increase in the number of surgical patients in the affected DRGs and a slight decrease for those in the unaffected ones.

Figures 3 and 4 show the time trends in the proportion of patients waiting more than 6 months and in the average length of stay. ${ }^{9}$ As shown in Figure 3, the proportion of patients waiting more than 6 months is higher for surgical than for medical treatments. We observe no relevant changes for the affected medical DRGs, whereas the unaffected ones display a limited variation until 2008, with a slight increase for the remaining period. For surgical treatments, the affected and unaffected DRGs follow broadly similar trends, with an increase in the proportion of patients waiting more than 6 months from 2005 to 2009 and a small reduction from 2009 to 2010 . Without further information, we can only speculate on the possible underlying factors leading to this observed change in the time trends for all DRGs. The general increase over the period 2005-2009 may result from the financial pressure faced by public hospitals, whereas the reverse trend observed over the last years of analysis may reflect the general attention devoted in Italy to reduce excessive waiting times (Agenas, 2011). Finally, inspection of the time trends in the average length of stay shown in Figure 4 highlights only negligible variations for all DRG groups before and after the policy change.

Lastly, it is important to note that while Figures $2-4$ provide useful descriptive information about the patterns of our dependent variables in the affected and unaffected DRG groups over time, they do not allow to account for differences across hospitals and DRGs, which are controlled for in formal regression models. It is only through the regression analysis performed in Section 5 that we formally test for the significance of the (short-run and medium-run) effects of the DRG price changes on the behaviour of public hospitals.

\subsection{Hospital characteristics}

Our sample comprises nine hospitals directly managed by ASLs and five AOs, with the latter having greater autonomy compared with ASL-run hospitals. We test whether AOs are more responsive to price changes

\footnotetext{
${ }^{9}$ Waiting times are calculated as the time span between the date of admission and the date of decision to admit.
} 


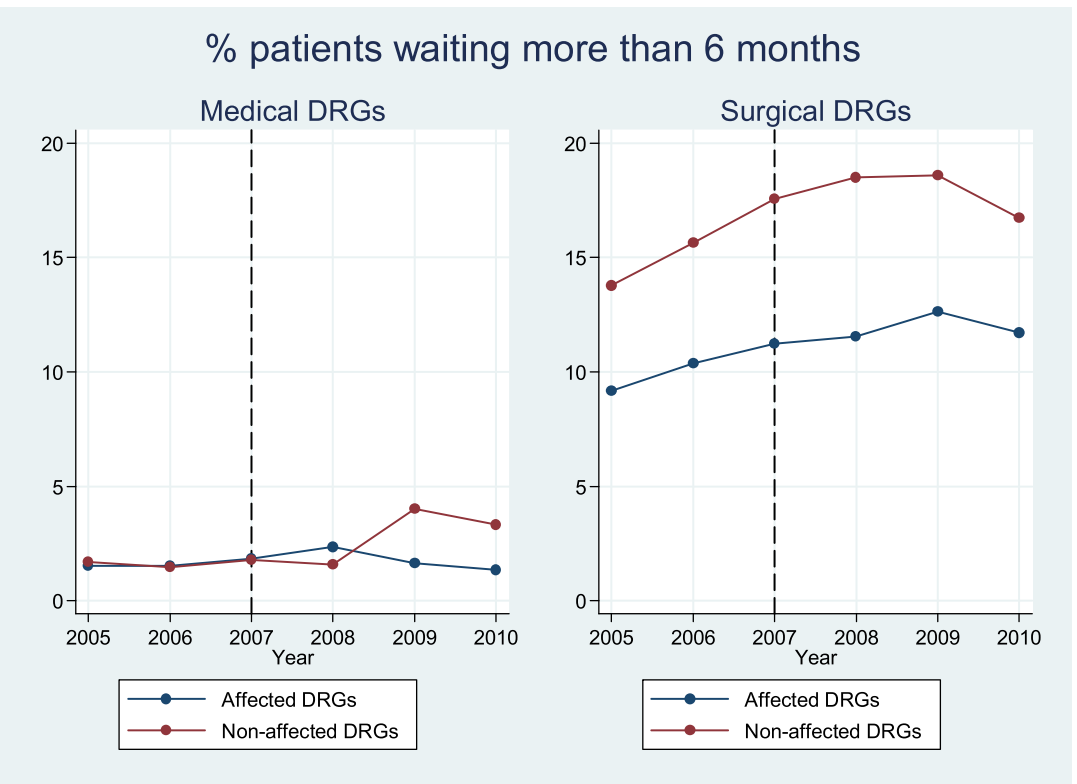

Figure 3. Percentage of elective patients waiting more than 6 months at all hospitals, by year and type of diagnosis-related groups (DRG)

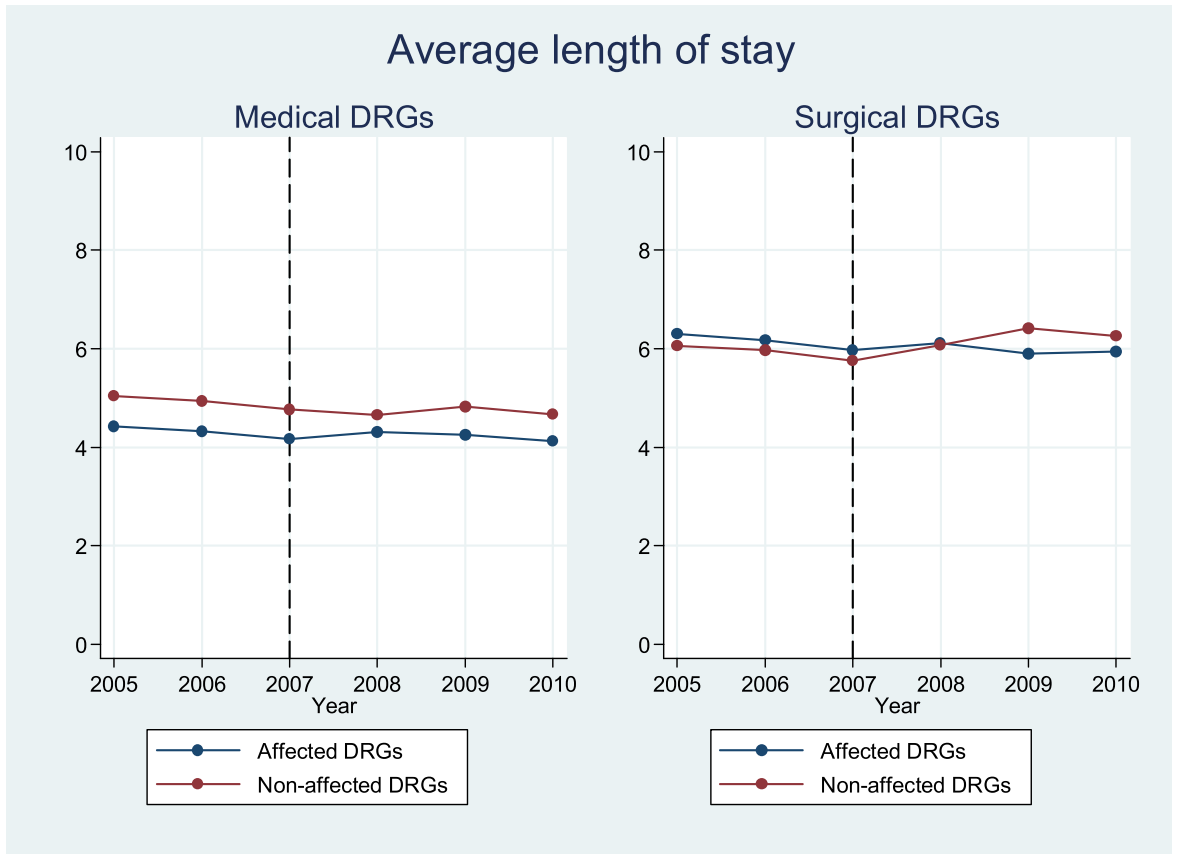

Figure 4. Average length of stay for patients discharged at all hospitals, by year and type of diagnosis-related group (DRG)

relative to hospitals directly managed by ASLs. This offers the opportunity to analyse whether responsiveness to financial incentives increases with the administrative and financial autonomy enjoyed by hospitals. The manager's roles differ across the two types of organisations. While in AOs, the manager is the principal at 
the top of a two-layer hierarchy, with the doctors being on the bottom layer; in ASL-run hospitals, he is the middle principal in a three-layer hierarchy, with the Local Health Authority being on the top layer. Altering the decision-making hierarchy may affect the incentives of the different decision-makers with potential consequences on hospital performance (Giuffrida et al., 1999).

In addition, we explore possible differences in hospitals' responses due to different pre-policy conditions as expressed in terms of the proportion of occupied beds before policy implementation. One may expect the policy change to have a greater impact on hospitals with higher levels of unused capacity prior to the price increase. To test this assumption, we use a pre-policy measure provided by the Health Department and computed as the ratio between the number of occupied beds and available beds in 2006. The variable is reported by hospital and type of DRGs (medical and surgical). Table II shows the summary statistics: for patients with medical conditions (panel A), the proportion of occupied beds in 2006 was $88 \%$ on average (range 81-93\%); for patients with surgical conditions (panel B), the proportion of occupied beds was $75 \%$ on average (range $69-83 \%$ ). We assigned the values of the proportion of occupied beds reported by a single hospital for the groups of medical and surgical DRGs in 2006 to the same hospital and type of DRGs in all years between 2005 and 2010. We then divided the sub-sample of surgical DRGs by low, medium and high tertiles of the occupancy rate distribution, and find that, for surgical patients, the proportion of occupied beds fell within one of the following ranges: up to $70 \%$ (low tertile), between $71 \%$ and $80 \%$ (medium tertile) and over $80 \%$ (high tertile). Because for medical procedures the proportion of occupied beds was always higher than $80 \%$, we only focus on surgical treatments to test for the influence of different pre-policy bed occupancy rates.

\section{ESTIMATION STRATEGY}

The policy of interest consists of a one-time increase in DRG prices, and our aim is to separately estimate its impact at successive points in time. Therefore, to properly identify the coefficients for the associated effects, the specification of the estimating equation requires the variable capturing the price change to be constant at the DRG level and equal to the difference in tariffs between the pre-policy and post-policy period in each year. To do so, we draw our baseline specification on Dafny (2005), with some modifications that account for the specific features of our data, reflecting in particular the distinction between short-run and medium-run effects. It can be represented as follows:

$$
y_{j h t}=Z_{j h}+T_{t}+\beta_{1} \Delta \ln (p)_{j} \times(\text { Short_run })_{t}+\beta_{2} \Delta \ln (p)_{j} \times(\text { Medium_run })_{t}+\beta_{3} H_{h} \times T_{t}+\beta_{4} D R G_{j} \times T+\varepsilon_{j h t}
$$

Equation 1 is estimated for different dependent variables. We define $y_{j h t}$ as the log of the number of inpatient discharges; the proportion of patients waiting more than 6 months; and the log of the average length of stay. We consider patients with the $j$-th DRG condition treated at hospital $h$ in year $t$. Because $y_{j h t}$ is expressed either in $\log$ terms or in percentage points, the estimated coefficients can be interpreted as elasticities.

Among the explanatory variables, we include DRG-by-hospital fixed effects, $Z_{j h}$, capturing time-invariant idiosyncratic characteristics of DRG $j$ in hospital $h$; and year fixed effects (with the baseline year set to 2006), $T_{t}$, which control for shocks common to all DRGs in all hospitals. The key explanatory variables are

Table II. Hospital bed occupancy rates, 2006 data

\begin{tabular}{lccccc}
\hline & Obs. & Mean & SD & Min & Max \\
\hline $\begin{array}{l}\text { Panel A: Medical DRGs } \\
\text { Bed occupancy rates }\end{array}$ & 1420 & 87.72 & 3.09 & 81.36 & 92.90 \\
$\begin{array}{l}\text { Panel B: Surgical DRGs } \\
\text { Bed occupancy rates }\end{array}$ & 1070 & 75.29 & 5.36 & 69.12 & 83.48 \\
\hline
\end{tabular}

DRGs, diagnosis-related groups. 
$\Delta \ln (p)_{j} \times(\text { Short_run })_{t}$ and $\Delta \ln (p)_{j} \times(\text { Medium_run })_{t}$. The first component of these interactions, $\Delta \ln (p)_{j}$, measures the difference $\ln (p)_{\text {jpost_shock }}-\ln (p)_{\text {jpre_shock }}$, where $p_{j p o s t \_s h o c k}$ is the price of DRG $j$ in the post-policy years and $p_{j p r e \_s h o c k}$ is the price of the same DRG before policy implementation. Thus, $\Delta \ln (p)_{j}$ takes a value greater than zero for the DRGs targeted by the price change, and zero otherwise. In order to examine the effect of the price change in the short-run and medium-run post-policy periods, we interact $\Delta \ln (p)_{j}$ with the dummies (Short_run), equal to one in the first 2 years after policy implementation (2007 and 2008), and zero otherwise; and (Medium_run), equal to one in the two subsequent years (2009 and 2010), and zero otherwise. Finally, we include the interactions of hospital dummies with year fixed effects, $H_{h} \times T_{t}$, in order to control for possible time-varying hospital characteristics common to all DRGs (for instance, staff employed), and the set of interactions between each DRG and a linear time trend, $D R G_{j} \times T$, which ensures that the estimated effects do not reflect unobserved DRG characteristics affecting the dependent variables in the form of linear time trends. ${ }^{10}$

We next estimate the following regression to investigate potential heterogeneous responses across hospitals by legal status:

$$
\begin{aligned}
\ln (y)_{j h t}=Z_{j h} & +T_{t}+\beta_{1} \Delta \ln (p)_{j} \times(\text { Short_run })_{t}+\beta_{2} \Delta \ln (p)_{j} \times(\text { Medium_run })_{t} \\
& +\beta_{3} \Delta \ln (p)_{j} \times(\text { Short_run })_{t} \times A S L_{h}+\beta_{4} \Delta \ln (p)_{j} \times(\text { Medium_run })_{t} \times A S L_{h} \\
& +\beta_{5} H_{h} \times T_{t}+\beta_{6} D R G_{j} \times T+\varepsilon_{j h t}
\end{aligned}
$$

where $A S L_{h}$ is a dummy variable taking the value one for ASL hospitals, and zero otherwise. Thus, the coefficients $\beta_{3}$ and $\beta_{4}$ now capture the differential effect (if any) for ASL hospitals relative to AOs in the shortrun and medium-run post-policy periods, respectively.

Finally, we investigate whether the response of hospitals varies depending on the proportion of occupied beds reported 1 year before policy implementation. This is performed by estimating

$$
\begin{aligned}
\ln (y)_{j h t}=Z_{j h} & +T_{t}+\beta_{1} \Delta \ln (p)_{j} \times(\text { Short_run })_{t}+\beta_{2} \Delta \ln (p)_{j} \times(\text { Medium_run })_{t} \\
& +\beta_{3} \Delta \ln (p)_{j} \times(\text { Short_run })_{t} \times M O_{h}+\beta_{4} \Delta \ln (p)_{j} \times(\text { Short_run })_{t} \times H O_{h} \\
& +\beta_{5} \Delta \ln (p)_{j} \times(\text { Medium_run })_{t} \times M O_{h}+\beta_{6} \Delta \ln (p)_{j} \times(\text { Medium_run })_{t} \times H O_{h} \\
& +\beta_{7} H_{h} \times T_{t}+\beta_{8} D R G_{j} \times T+\varepsilon_{j h t}
\end{aligned}
$$

where $M O_{h}$ and $H O_{h}$ are dummy variables for each hospital $h$, which take value one for hospitals within the medium and high tertiles of the occupancy rate distribution, and zero otherwise. ${ }^{11}$ Thus, the coefficients $\beta_{1}$ and $\beta_{2}$ now capture the effect of a price increase for hospitals within the low tertile of the occupancy rate distribution (the reference category) in the short-run and medium-run, respectively. The additional effects for those falling within the medium and high tertiles are given by, respectively, $\beta_{3}$ and $\beta_{5}$ in the short-run, and $\beta_{4}$ and $\beta_{6}$ in the medium-run. If larger responses occur for hospitals characterised by higher levels of unused capacity before policy change, the estimated coefficients $\beta_{3}-\beta_{6}$ will be negative. We present here the results of Eqn (3) only on the sub-sample of surgical patients because, as previously highlighted, for medical patients, the proportion of occupied beds reported by hospitals in year 2006 was always higher than $80 \%$ across all sample hospitals.

\section{RESULTS}

Table III presents the results for Eqn (1), estimated for medical and surgical DRGs separately. The dependent variable for the estimates reported in the first two columns is the number of inpatient discharges. Our findings

\footnotetext{
${ }^{10}$ Differently from Dafny (2005) that uses data aggregated at the DRG-year level, in our regressions, the unit of analysis is represented by DRG-hospital-year cells, where the hospital and DRG main effects are absorbed into the DRG-by-hospital fixed effects, $Z_{j h}$. Following previous studies (e.g. Dafny, 2005; Januleviciute et al., 2015), we use DRG-specific linear time trends as a feasible alternative to DRG-year interactions.

${ }^{11}$ See Section 3.3 for the details on how these variables were generated.
} 
Table III. Average price effects on the number of inpatient discharges, $\%$ of patients waiting more than 6 months and average length of stay

\begin{tabular}{|c|c|c|c|c|c|c|}
\hline & \multicolumn{2}{|c|}{$\begin{array}{c}\ln \text { (number of inpatient } \\
\text { discharges) }\end{array}$} & \multicolumn{2}{|c|}{$\begin{array}{l}\% \text { patients waiting more than } \\
66 \text { months }\end{array}$} & \multicolumn{2}{|c|}{$\ln$ (average length of stay) } \\
\hline & $\begin{array}{l}\text { Medical } \\
\text { DRGs }\end{array}$ & $\begin{array}{l}\text { Surgical } \\
\text { DRGs }\end{array}$ & $\begin{array}{l}\text { Medical } \\
\text { DRGs }\end{array}$ & $\begin{array}{l}\text { Surgical } \\
\text { DRGs }\end{array}$ & $\begin{array}{l}\text { Medical } \\
\text { DRGs }\end{array}$ & $\begin{array}{c}\text { Surgical } \\
\text { DRGs }\end{array}$ \\
\hline$\Delta \ln (\mathrm{p}) \times($ Short_run $)$ & $\begin{array}{r}-0.214 \\
(0.628)\end{array}$ & $\begin{array}{l}1.733 * * \\
(0.584)\end{array}$ & $\begin{array}{r}-0.050 \\
(0.073)\end{array}$ & $\begin{array}{r}-0.170 \\
(0.165)\end{array}$ & $\begin{array}{l}0.115 \\
(0.265)\end{array}$ & $\begin{array}{c}0.095 \\
(0.486)\end{array}$ \\
\hline$\Delta \ln (\mathrm{p}) \times($ Medium_run $)$ & $\begin{array}{c}0.281 \\
(0.915)\end{array}$ & $\begin{array}{l}3.973 * * * \\
(1.127)\end{array}$ & $\begin{array}{r}-0.101 \\
(0.159)\end{array}$ & $\begin{array}{r}-0.175 \\
(0.300)\end{array}$ & $\begin{array}{c}0.329 \\
(0.611)\end{array}$ & $\begin{array}{c}0.041 \\
(0.703)\end{array}$ \\
\hline Hospital-DRG fixed effects & $\mathrm{Y}$ & $\mathrm{Y}$ & $\mathrm{Y}$ & $\mathrm{Y}$ & $\mathrm{Y}$ & $\mathrm{Y}$ \\
\hline Year fixed effects & $\mathrm{Y}$ & $\mathrm{Y}$ & $\mathrm{Y}$ & $\mathrm{Y}$ & $\mathrm{Y}$ & $\mathrm{Y}$ \\
\hline Hospital $\times$ Year fixed effects & $\mathrm{Y}$ & $\mathrm{Y}$ & $\mathrm{Y}$ & $\mathrm{Y}$ & $\mathrm{Y}$ & $\mathrm{Y}$ \\
\hline DRG trends & $\mathrm{Y}$ & $\mathrm{Y}$ & $\mathrm{Y}$ & $\mathrm{Y}$ & $\mathrm{Y}$ & $\mathrm{Y}$ \\
\hline Adj. R-squared & 0.765 & 0.863 & 0.199 & 0.414 & 0.467 & 0.659 \\
\hline Obs. & 8251 & 6265 & 8251 & 6265 & 8251 & 6265 \\
\hline
\end{tabular}

DRGs, diagnosis-related groups.

Robust standard errors clustered at the hospital level are in parentheses.

$* p<0.1, * * p<0.05, * * * p<0.01$.

indicate that an increase in medical DRG prices did not lead to significant changes in the volume of medical activity for the affected DRGs relative to the unaffected ones. By contrast, we find that a $1 \%$ increase in the price of surgical DRGs increased the volume of surgical activity for the affected DRGs, as compared with the unaffected ones, by an amount of $1.7 \%$ in the short-run and $4 \%$ in the medium-run. The remaining columns of Table III display the results for the other outcomes of interest and show that an increase in DRG prices had a negative but not significant impact on the proportion of patients waiting more than 6 months, and a positive but, again, not significant impact on average length of stay.

We then examine the influence of hospital legal status using the specification proposed in Eqn (2). As Table IV shows, we do not find significant differences in the response patterns between the two groups of hospitals for any outcome considered, suggesting that the reaction of public hospitals to changes in DRG prices does not seem to be affected by the degree of their administrative and financial independence.

Table V shows the results from Eqn (3), where we consider the role of pre-policy levels of unused capacity. With respect to the volume of surgical activity, we find evidence that an increase in DRG prices led to a larger response for hospitals holding a higher excess capacity before policy change. Specifically, hospitals falling within the lowest tertile of the occupancy rate distribution (our baseline category) display a positive and significant impact both in the short-run and in the medium-run post-policy periods by an amount equal to $2.6 \%$ and $6 \%$, respectively. This effect is significantly lower for hospitals within the medium tertile and becomes statistically insignificant for hospitals with a bed occupancy rate higher than $80 \%$ (highest tertile). ${ }^{12}$ In terms of the proportion of patients waiting more than 6 months, the policy change had a negative and significant (at the $10 \%$ level) impact for hospitals with the lowest bed occupancy rates, whereas the effect becomes statistically insignificant for hospitals holding higher bed occupancy rates. Finally, our results on the average length of stay suggest that an increase in DRG prices produced no significant effect irrespective of the pre-policy levels of unused capacity. ${ }^{13}$

\footnotetext{
${ }^{12}$ Bearing in mind that the total effect for these hospitals is captured by the sum $\left(\beta_{1}+\beta_{3}\right)$ in the short-run, and by $\left(\beta_{1}+\beta_{5}\right)$ in the mediumrun.

${ }^{13}$ We repeated the regression analysis on the sub-sample of medical DRGs, after grouping the occupancy rate distribution that we observe for these treatments by low, medium and high tertiles. In general, we do not detect any significant difference in the response of hospitals according to their proportion of occupied beds reported in the pre-policy period. The only exception is for volume of activity: we find a positive but not significant effect for hospitals falling within the low and medium tertiles, and a significantly smaller effect for the remaining hospitals. These results are available upon request.
} 
Table IV. Responses to the policy change by legal status

\begin{tabular}{|c|c|c|c|c|c|c|}
\hline & \multicolumn{2}{|c|}{$\begin{array}{c}\ln \text { (number of inpatient } \\
\text { discharges) }\end{array}$} & \multicolumn{2}{|c|}{$\begin{array}{c}\% \text { patients waiting more than } \\
6 \text { months }\end{array}$} & \multicolumn{2}{|c|}{$\ln$ (average length of stay) } \\
\hline & $\begin{array}{l}\text { Medical } \\
\text { DRGs }\end{array}$ & $\begin{array}{l}\text { Surgical } \\
\text { DRGs }\end{array}$ & $\begin{array}{l}\text { Medical } \\
\text { DRGs }\end{array}$ & $\begin{array}{l}\text { Surgical } \\
\text { DRGs }\end{array}$ & $\begin{array}{l}\text { Medical } \\
\text { DRGs }\end{array}$ & $\begin{array}{l}\text { Surgical } \\
\text { DRGs }\end{array}$ \\
\hline$\Delta \ln (\mathrm{p}) \times($ Short_run $)$ & $\begin{array}{r}-0.207 \\
(0.699)\end{array}$ & $\begin{array}{l}1.961 * * \\
(0.697)\end{array}$ & $\begin{array}{r}-0.030 \\
(0.069)\end{array}$ & $\begin{array}{c}-0.363^{*} \\
(0.200)\end{array}$ & $\begin{array}{c}0.429 \\
(0.354)\end{array}$ & $\begin{array}{c}0.085 \\
(0.592)\end{array}$ \\
\hline$\Delta \ln (\mathrm{p}) \times($ Short_run $) \times$ ASL & $\begin{array}{c}-0.011 \\
(0.784)\end{array}$ & $\begin{array}{c}-0.381 \\
(0.626)\end{array}$ & $\begin{array}{c}-0.034 \\
(0.075)\end{array}$ & $\begin{array}{c}0.325 \\
(0.206)\end{array}$ & $\begin{array}{c}-0.545 \\
(0.325)\end{array}$ & $\begin{array}{c}0.020 \\
(0.448)\end{array}$ \\
\hline$\Delta \ln (\mathrm{p}) \times($ Medium_run $)$ & $\begin{array}{c}0.251 \\
(1.216)\end{array}$ & $\begin{array}{l}3.721 * * \\
(1.622)\end{array}$ & $\begin{array}{r}-0.104 \\
(0.153)\end{array}$ & $\begin{array}{c}-0.200 \\
(0.414)\end{array}$ & $\begin{array}{c}0.622 \\
(0.669)\end{array}$ & $\begin{array}{r}-0.283 \\
(0.797)\end{array}$ \\
\hline$\Delta \ln (\mathrm{p}) \times($ Medium_run $) \times \mathrm{ASL}$ & $\begin{array}{c}0.054 \\
(0.859)\end{array}$ & $\begin{array}{l}0.428 \\
(1.224)\end{array}$ & $\begin{array}{l}0.007 \\
(0.063)\end{array}$ & $\begin{array}{c}0.043 \\
(0.353)\end{array}$ & $\begin{array}{c}-0.500 \\
(0.367)\end{array}$ & $\begin{array}{r}0.551 \\
(0.394)\end{array}$ \\
\hline Hospital-DRG fixed effects & $\mathrm{Y}$ & $\mathrm{Y}$ & $\mathrm{Y}$ & $\mathrm{Y}$ & $\mathrm{Y}$ & $\mathrm{Y}$ \\
\hline Year fixed effects & $\mathrm{Y}$ & $\mathrm{Y}$ & $\mathrm{Y}$ & $\mathrm{Y}$ & $\mathrm{Y}$ & $\mathrm{Y}$ \\
\hline Hospital $\times$ Year fixed effects & $\mathrm{Y}$ & $\mathrm{Y}$ & $\mathrm{Y}$ & $\mathrm{Y}$ & $\mathrm{Y}$ & $\mathrm{Y}$ \\
\hline DRG trends & $\mathrm{Y}$ & $\mathrm{Y}$ & $\mathrm{Y}$ & $\mathrm{Y}$ & $\mathrm{Y}$ & $\mathrm{Y}$ \\
\hline Adj. R-squared & 0.765 & 0.863 & 0.199 & 0.414 & 0.467 & 0.659 \\
\hline Obs. & 8251 & 6265 & 8251 & 6265 & 8251 & 6265 \\
\hline
\end{tabular}

DRGs, diagnosis-related groups; ASL, Aziende Sanitarie Locali.

Robust standard errors clustered at the hospital level are in parentheses.

$* p<0.1{ }^{* *} p<0.05$. $* * * p<0.01$.

Finally, we test the restriction imposed by Eqns (1)-(3), where we estimated the impact of the price increase on our outcome variables by grouping years 2007-2008 into short-run post-policy period and years 2009-2010 into medium-run post-policy period. By doing so, we are implicitly assuming that the effect of the price increase was not significantly different between 2007 and 2008 and between 2009 and 2010. In Table VI, we show the results from a more flexible estimation specification, where we replaced the interaction terms $\Delta \ln$ $(p)_{j} \times(\text { Short_run })_{t}$ and $\Delta \ln (p)_{j} \times(\text { Medium_run })_{t}$ with the set of interactions $\sum_{t=2007}^{2010} \Delta \ln (p)_{j} \times T_{t}$, where $T_{t}$ is a dummy variable for year $t$. The results provided by this flexible specification show the similarity of the effects between years 2007 and 2008 and between 2009 and $2010 .^{14}$

\section{VALIDITY OF THE ESTIMATION SPECIFICATION}

The identification of the causal effect of the price change is challenged by the underlying non-random selection of the targeted DRGs, a limitation shared by most large-scale policy interventions. However, the policy design and the identification strategy allow us to account for policy endogeneity.

The targeted DRGs were identified according to data on costs aggregated at the specialty level and collected from a subset of regional hospitals in 2005, 2 years before the policy change. This provided policymakers only with rough indications on the cost-compensation gap across DRGs. Moreover, the available information on costs was partially outdated in 2007. Given this background, the policymaker's decision was to implement tariff changes that were largely uniform across DRGs rather than to fine-tune the adjustments according to DRGspecific tariff-cost gaps, thus leading to changes in tariffs that were poorly correlated to the actual costs experienced in the majority of hospitals in $2007 .^{15}$

\footnotetext{
${ }^{14}$ We find no significant difference between the effects in 2007 and 2008, and between the effects in 2009 and 2010.

${ }^{15}$ The tariff increase was in most cases set at the uniform rate of $4 \%$. Moreover, it was not replicated in the following four years, confirming that it was intended as a one-time price shock.
} 
Table V. Responses to the policy change by bed occupancy rate

\begin{tabular}{|c|c|c|c|}
\hline & $\begin{array}{c}\ln \text { (number of inpatient } \\
\text { discharges) }\end{array}$ & $\begin{array}{l}\% \text { patients waiting more } \\
\text { than } 6 \text { months }\end{array}$ & $\ln$ (average length of stay) \\
\hline & Surgical DRGs & Surgical DRGs & Surgical DRGs \\
\hline$\Delta \ln (\mathrm{p}) \times($ Short_run $)$ & $\begin{array}{l}2.595 * * \\
(1.078)\end{array}$ & $\begin{array}{c}-0.251^{*} \\
(0.135)\end{array}$ & $\begin{array}{c}0.563 \\
(0.631)\end{array}$ \\
\hline$\Delta \ln (\mathrm{p}) \times($ Short_run $) \times \mathrm{MO}$ & $\begin{array}{r}-0.781 \\
(0.741)\end{array}$ & $\begin{array}{l}0.027 \\
(0.289)\end{array}$ & $\begin{array}{r}-0.877 \\
(0.498)\end{array}$ \\
\hline$\Delta \ln (\mathrm{p}) \times($ Short_run $) \times \mathrm{HO}$ & $\begin{array}{l}-1.926 * * \\
(0.865)\end{array}$ & $\begin{array}{c}0.232 \\
(0.326)\end{array}$ & $\begin{array}{r}-0.532 \\
(0.424)\end{array}$ \\
\hline$\Delta \ln (\mathrm{p}) \times($ Medium_run $)$ & $\begin{array}{l}5.980 * * * \\
(1.530)\end{array}$ & $\begin{array}{r}-0.287 \\
(0.382)\end{array}$ & $\begin{array}{c}0.767 \\
(0.713)\end{array}$ \\
\hline$\Delta \ln (\mathrm{p}) \times($ Medium_run $) \times \mathrm{MO}$ & $\begin{array}{l}-2.331 * * \\
(0.940)\end{array}$ & $\begin{array}{r}0.0987 \\
(0.519)\end{array}$ & $\begin{array}{l}-1.306^{* * *} \\
(0.467)\end{array}$ \\
\hline$\Delta \ln (\mathrm{p}) \times($ Medium_run $) \times \mathrm{HO}$ & $\begin{array}{l}-3.845 * * * \\
(0.770)\end{array}$ & $\begin{array}{l}0.248 \\
(0.519)\end{array}$ & $\begin{array}{r}-0.876 \\
(0.504)\end{array}$ \\
\hline Hospital-DRG fixed effects & $\mathrm{Y}$ & $\mathrm{Y}$ & $\mathrm{Y}$ \\
\hline Year fixed effects & $\mathrm{Y}$ & $\mathrm{Y}$ & $\mathrm{Y}$ \\
\hline Hospital $\times$ Year fixed effects & $\mathrm{Y}$ & $\mathrm{Y}$ & $\mathrm{Y}$ \\
\hline DRG trends & $\mathrm{Y}$ & $\mathrm{Y}$ & $\mathrm{Y}$ \\
\hline Adj. R-squared & 0.864 & 0.413 & 0.659 \\
\hline Obs. & 6265 & 6265 & 6265 \\
\hline
\end{tabular}

DRGs, diagnosis-related groups; $\mathrm{MO}=1$ for hospitals within the medium tertile of the occupancy rate distribution, 0 otherwise; $\mathrm{HO}=1$ for hospitals within the high tertile of the occupancy rate distribution, 0 otherwise.

Robust standard errors clustered at the hospital level are in parentheses.

${ }^{*} p<0.1 . * * p<0.05$. ${ }^{* * *} p<0.01$.

Table VI. Flexible specification

\begin{tabular}{|c|c|c|c|c|c|c|}
\hline & \multicolumn{2}{|c|}{$\begin{array}{c}\ln \text { (number of inpatient } \\
\text { discharges) }\end{array}$} & \multicolumn{2}{|c|}{$\begin{array}{l}\% \text { patients waiting more than } \\
6 \text { months }\end{array}$} & \multicolumn{2}{|c|}{$\ln$ (average length of stay) } \\
\hline & $\begin{array}{l}\text { Medical } \\
\text { DRGs }\end{array}$ & $\begin{array}{l}\text { Surgical } \\
\text { DRGs }\end{array}$ & $\begin{array}{l}\text { Medical } \\
\text { DRGs }\end{array}$ & $\begin{array}{l}\text { Surgical } \\
\text { DRGs }\end{array}$ & $\begin{array}{l}\text { Medical } \\
\text { DRGs }\end{array}$ & $\begin{array}{l}\text { Surgical } \\
\text { DRGs }\end{array}$ \\
\hline \multirow[t]{2}{*}{$\Delta \ln (\mathrm{p}) \times($ Year2007 $)$} & 0.117 & $2.029 * *$ & 0.067 & -0.241 & 0.030 & -0.069 \\
\hline & $(0.746)$ & (0.818) & (0.114) & $(0.224)$ & $(0.433)$ & $(0.523)$ \\
\hline \multirow[t]{2}{*}{$\Delta \ln (\mathrm{p}) \times($ Year2008) } & 0.485 & $3.197 * *$ & 0.289 & -0.444 & -0.294 & 0.179 \\
\hline & $(0.993)$ & (1.410) & $(0.204)$ & $(0.308)$ & $(0.671)$ & $(0.564)$ \\
\hline \multirow[t]{2}{*}{$\Delta \ln (\mathrm{p}) \times($ Year2009 $)$} & 1.099 & $5.657 * *$ & 0.292 & -0.492 & -0.141 & 0.116 \\
\hline & $(1.251)$ & $(2.091)$ & $(0.314)$ & $(0.393)$ & (1.069) & $(0.687)$ \\
\hline \multirow[t]{2}{*}{$\Delta \ln (\mathrm{p}) \times($ Year2010 $)$} & 1.516 & $5.814^{*}$ & 0.414 & -0.548 & -0.185 & -0.193 \\
\hline & $(1.601)$ & $(2.779)$ & $(0.428)$ & $(0.570)$ & $(1.357)$ & $(0.846)$ \\
\hline Hospital-DRG fixed effects & $\mathrm{Y}$ & $\mathrm{Y}$ & $\mathrm{Y}$ & $\mathrm{Y}$ & $\mathrm{Y}$ & $\mathrm{Y}$ \\
\hline Year fixed effects & $\mathrm{Y}$ & $\mathrm{Y}$ & $\mathrm{Y}$ & Y & $\mathrm{Y}$ & $\mathrm{Y}$ \\
\hline Hospital $\times$ Year fixed effects & $\mathrm{Y}$ & $\mathrm{Y}$ & $\mathrm{Y}$ & Y & $\mathrm{Y}$ & $\mathrm{Y}$ \\
\hline DRG trends & $\mathrm{Y}$ & $\mathrm{Y}$ & $\mathrm{Y}$ & $\mathrm{Y}$ & $\mathrm{Y}$ & $\mathrm{Y}$ \\
\hline Adj. R-squared & 0.765 & 0.863 & 0.199 & 0.414 & 0.467 & 0.659 \\
\hline Obs. & 8251 & 6265 & 8251 & 6265 & 8251 & 6265 \\
\hline
\end{tabular}

DRGs, diagnosis-related groups.

Robust standard errors clustered at the hospital level are in parentheses.

$* p<0.1 . * * p<0.05$. ***p $<0.01$.

Besides the institutional features discussed earlier, the empirical strategy further mitigates possible concerns over potential endogeneity issues. First, we explicitly account for possible differences in the dependent variables between affected and unaffected DRGs that may have been caused by factors other than the policy change. For this purpose, we control for fixed differences in hospital performance between 
the two diagnoses groups via the DRG-by-hospital fixed effects. Thus, all time-invariant differences between DRGs that may affect the outcome variables of interest will be absorbed into the DRG-byhospital fixed effects. Time-varying changes common to all DRGs are captured by the year fixed effects. Moreover, we followed prior studies (e.g. Dafny, 2005; Januleviciute et al., 2015) by including DRGspecific time trends in order to control for the possible variation in hospital performance across DRGs over time.

Second, we also consider the possibility that time-varying (unobserved) confounding factors may be correlated to both increases in DRG tariffs and differential trends in hospital performance between affected and unaffected DRGs in the pre-policy period. We test for this by performing a falsification test similar to the one adopted in previous studies (Clemens and Gottlieb, 2014, among others). We check for pre-existing trends correlated with price changes by adding to the baseline specification illustrated in Eqn (1) the interaction between the log ratio in the DRG prices after and prior to the policy change, $\Delta \ln (p)_{j}$, and a dummy variable for the pre-policy year 2005. The premise is that, because DRG prices did not change before 2007, we should not expect to find a significant coefficient for this interaction term. By contrast, the presence of a significant effect would be consistent with the hypothesis of different pre-existing trends in the dependent variables, which would challenge the identification of the estimated impact of the policy change. The results of this falsification test are presented in Table VII; the interaction coefficients with year 2005 are not statistically significant, while the estimated coefficients for the other key covariates remain stable. As we find no evidence that the price change was correlated with pre-existing trends in the dependent variables, this result supports our identification strategy.

To reinforce the contention that our results are not capturing a spurious effect, we also repeat our analysis on non-elective patients. Because non-elective patients need immediate treatment (within $48 \mathrm{~h}$ ), hospitals cannot rely on waiting times to ration demand for these patients. As long as the provision of nonelective care is outside hospital control, one should expect price changes to generate a smaller (or no) impact on non-elective treatments. On the contrary, in the case of a spurious price effect, price changes may be found to affect both elective and non-elective admissions. The results from this placebo test are reported in Table A1 in the Appendix. For non-elective patients, we find no significant effect on any outcome of interest, a result which goes in favour of our claim of a genuine causal effect induced by the change in DRG prices.

Finally, we address the potential omitted variable problem resulting from the absence of controls for patient severity from our main specification and test the robustness of the estimated price effects to the inclusion of information that captures patients' comorbidity. For this purpose, we have performed our analysis adding to the set of controls the Charlson comorbidity index (CCI) as a measure of patient severity (Charlson et al., 1987; Stagg, 2006). First, we have computed the CCI at the patient level using the International Classification of Disease, Ninth Revision, Clinical Modification diagnosis codes included in the hospital discharge data, and then we have generated the mean values for the CCI at the hospital-DRG-year level. The results, in particular those concerning the coefficients on the price effects, are by and large unaffected by the inclusion of the CCI and come out very close to those reported herein. ${ }^{16}$

\section{DISCUSSION AND CONCLUSIONS}

This paper investigates the impact of a policy change implemented in Italy's region Emilia-Romagna, which increased the price of a subset of DRGs by $6 \%$ on average. Our contribution to the literature spans over several dimensions: we examine hospital response in terms of the number of inpatient discharges, waiting times and length of stay; we explore potential differences between short-run and medium-run

\footnotetext{
${ }^{16} \mathrm{We}$ thank an anonymous referee for highlighting this point. The full set of results is available upon request.
} 
Table VII. Falsification test of pre-existing trends correlated with the price changes

\begin{tabular}{|c|c|c|c|c|c|c|}
\hline & \multicolumn{2}{|c|}{$\begin{array}{c}\ln \text { (number of inpatient } \\
\text { discharges) }\end{array}$} & \multicolumn{2}{|c|}{$\begin{array}{l}\% \text { patients waiting more than } \\
6 \text { months }\end{array}$} & \multicolumn{2}{|c|}{$\ln$ (average length of stay) } \\
\hline & $\begin{array}{l}\text { Medical } \\
\text { DRGs }\end{array}$ & $\begin{array}{l}\text { Surgical } \\
\text { DRGs }\end{array}$ & $\begin{array}{l}\text { Medical } \\
\text { DRGs }\end{array}$ & $\begin{array}{l}\text { Surgical } \\
\text { DRGs }\end{array}$ & $\begin{array}{l}\text { Medical } \\
\text { DRGs }\end{array}$ & $\begin{array}{l}\text { Surgical } \\
\text { DRGs }\end{array}$ \\
\hline$\Delta \ln (p) \times($ Pre_policy $)$ & $\begin{array}{c}0.392 \\
(0.400)\end{array}$ & $\begin{array}{c}0.662 \\
(0.749)\end{array}$ & $\begin{array}{c}0.173 \\
(0.113)\end{array}$ & $\begin{array}{r}-0.130 \\
(0.159)\end{array}$ & $\begin{array}{c}-0.187 \\
(0.297)\end{array}$ & $\begin{array}{r}-0.030 \\
(0.252)\end{array}$ \\
\hline$\Delta \ln (\mathrm{p}) \times($ Short_run $)$ & $\begin{array}{r}-0.287 \\
(0.626)\end{array}$ & $\begin{array}{l}1.619 * * \\
(0.616)\end{array}$ & $\begin{array}{r}-0.082 \\
(0.080)\end{array}$ & $\begin{array}{r}-0.148 \\
(0.169)\end{array}$ & $\begin{array}{c}0.150 \\
(0.254)\end{array}$ & $\begin{array}{c}0.100 \\
(0.501)\end{array}$ \\
\hline$\Delta \ln (\mathrm{p}) \times($ Medium_run $)$ & $\begin{array}{r}-0.064 \\
(0.968)\end{array}$ & $\begin{array}{l}3.416^{* *} \\
(1.218)\end{array}$ & $\begin{array}{c}-0.253 \\
(0.165)\end{array}$ & $\begin{array}{r}-0.066 \\
(0.348)\end{array}$ & $\begin{array}{c}0.494 \\
(0.529)\end{array}$ & $\begin{array}{c}0.067 \\
(0.812)\end{array}$ \\
\hline Hospital-DRG fixed effects & $\mathrm{Y}$ & $\mathrm{Y}$ & $\mathrm{Y}$ & $\mathrm{Y}$ & $\mathrm{Y}$ & $\mathrm{Y}$ \\
\hline Year fixed effects & Y & Y & Y & Y & Y & $\mathrm{Y}$ \\
\hline Hospital $\times$ Year fixed effects & $\mathrm{Y}$ & Y & $\mathrm{Y}$ & $\mathrm{Y}$ & $\mathrm{Y}$ & $\mathrm{Y}$ \\
\hline DRG trends & Y & Y & Y & Y & Y & Y \\
\hline Adj. R-squared & 0.765 & 0.863 & 0.199 & 0.414 & 0.467 & 0.659 \\
\hline Obs. & 8251 & 6265 & 8251 & 6265 & 8251 & 6265 \\
\hline
\end{tabular}

DRGs, diagnosis-related groups.Robust standard errors clustered at the hospital level are in parentheses. ${ }^{*} p<0.1$. $^{*} p<0.05$. *** $p<0.01$.

effects and assess whether the magnitude of the response is affected by hospital legal status; finally, we analyse the role of unused capacity as a factor that may contribute to explaining the variation in hospital responses.

The analysis is conducted within an NHS-type health system characterised by a dominant role of public suppliers, where the public sector encourages providers to co-operate in the planning of health services. Within this context, our results contribute to a better understanding of whether and how average payment incentives created by DRG price changes affect hospital behaviour, and provide useful policy insights into this issue. Although the mandate to meet the health needs of the reference population and the political accountability of public hospitals may weaken their responsiveness to financial incentives, variations in DRG prices may still matter also within national healthcare systems, in particular if public hospitals are required to avoid financial losses, which could lead to ward closures or to the dismissal of chief executives, and are allowed to retain financial surpluses for improving healthcare services. Moreover, in the institutional setting that we analyse, there is limited scope for inter-hospital competition, both within the public healthcare sector and between public and private providers, with the latter being allowed to play only a residual role. Under such weak competitive pressures, it is particularly interesting to examine the response of public hospitals to financial incentives, as this may reflect a positive weight given to the financial component of their objective function, net of the potential influence of significant competitive forces. ${ }^{17}$

Our findings indicate that the use of financial incentives taking the form of a one-time increase in DRG tariffs comes out as effective in influencing hospital behaviour, at least in terms of inpatient volumes. More precisely, we find that, on average, public hospitals responded to the increase in DRG prices by significantly expanding their volume of activity provided to surgical (elective) patients for the diagnoses affected by the price change relative to the unaffected ones. The magnitude of the effect also increased from the short-run to the medium-run: a $1 \%$ increase in the price of surgical DRGs led to an increase in the number of patients treated with the affected DRGs relative to the unaffected ones by $1.7 \%$ in the short-run and by $4 \%$ in the medium-run. This suggests that hospitals may require a non-negligible lag of time before they manage to fully adjust their activity in response to a change in DRG prices. Consequently, policymakers willing to stimulate the provision of given treatments through a tariff increase should consider that the

\footnotetext{
${ }^{17}$ See Barros and Siciliani (2012) for references to studies where public hospitals are modelled as pursuing profit-increasing activities at least to some extent.
} 
policy may fully display its effects only some years after implementation. Moreover, our analysis does not reject the hypothesis of homogeneous responses by hospital legal status, suggesting that the influence of financial incentives on the performance of public hospitals holds regardless of their degree of financial and administrative autonomy.

Our study also offers some insights into the channels through which public hospitals responded to the observed changes in DRG tariffs. In particular, we find evidence of heterogeneous responses according to hospitals' excess capacity in the pre-policy period, with the hospitals characterised by a lower proportion of occupied beds being relatively more responsive. ${ }^{18}$ For medical DRGs, we find no significant effect in terms of volume of activity. Since hospitals had a higher proportion of occupied beds for these diagnoses prior to the tariff increase, this finding is in line with the expectation that hospitals with higher unused capacity before policy implementation are more responsive to the price change.

At the same time, we find no or little evidence of a price effect for length of stay and waiting times. ${ }^{19}$ This suggests that hospitals do not appear to react to the policy change by adjusting patients' average length of stay at the DRG level, and that increasing DRG tariffs may not always be an effective tool to affect patients' prioritisation. It is important to bear in mind, however, that some of these results may be context specific to some degree. For instance, the average length of stay was pretty short already before policy implementation, thus limiting the scope for improving hospital efficiency through further reductions.

Although somewhat surprising, our finding that an increase in the number of patients treated is associated with no or little impact on the average length of stay and on waiting times can be rationalised in the following way: if both average length of stay and number of beds remain constant over time, as in the period covered by our study, hospitals may still expand their activity by increasing the bed occupancy rate. This is consistent with our result that hospitals experiencing a higher increase in the number of patients treated were those holding a greater excess capacity before policy implementation. Even if an increase in the bed occupancy rate generates a downward pressure on waiting times, this may bring forward previously latent demand, thereby totally or partially offsetting possible beneficial effects in terms of shorter waits.

While the present analysis is confined to the impact of a health policy undertaken in one specific area of Italy, the Emilia-Romagna region, still it can provide useful policy indications for more general settings. Given the considerable autonomy enjoyed by regional governments in the organisation of their healthcare systems and of the large north-south divide, single Italian regions cannot be considered fully representative of the entire Italian NHS. ${ }^{20}$ Nevertheless, Emilia-Romagna shares important common features with the other centre-north regions of Italy, which cover the majority of the country population and represent a relatively homogeneous group in terms of capital inputs, levels of activity and financial and non-financial performances. ${ }^{21}$ In terms of health outcomes, consistent evidence suggests that all the best performing regions are those of the centre-north of the country, and the standards of Emilia-Romagna are broadly comparable

\footnotetext{
${ }^{18}$ Such finding may also help to explain the result of Januleviciute et al. (2015) about the low price effect on the number of patients treated in Norway. Indeed, among the Organisation for Economic Co-operation and Development (OECD) countries, in the Norwegian case, we observe one of the highest rates of hospital bed occupancy, being equal to 93\% in 2010 against the OECD average 78\% (OECD, 2013). Hence, the limited capability of Norwegian hospitals to increase their volume of activity in response to an increase in DRG prices may also be due to their high bed occupancy rates.

${ }^{19}$ In principle, the stimulus to increase hospital activity in response to the policy change may induce hospitals to shorten waiting times. Although not statistically significant in the majority of cases, the direction of our findings support this hypothesis for patients that reported longer waiting times (in our study, for surgical rather than medical patients), and that the negative effect on waiting times increases with the level of unused capacity reported before policy implementation.

${ }^{20}$ This institutional heterogeneity is reflected in a general shift in the literature, with an increased number of studies covering single Italian regions. Focusing on a more homogenous institutional and socio-economic context favours a more clear-cut identification of the impact of the policy considered (e.g. see Berta et al., 2010 and Martini et al., 2014 for the effects of DRG changes in the Lombardy region).

${ }^{21}$ For instance, the number of hospital beds and the hospitalisation rate in Emilia-Romagna are very close to those recorded in the other centre-north regions, while in the rest of the country, we observe a lower hospital production capacity and larger hospitalisation rates (Ministry of Health, 2011).
} 
with the other regions of this area. ${ }^{22}$ Emilia-Romagna has also acquired a prominent institutional role within the Italian NHS, because it has been included among the five regions eligible for assessing the healthcare needs of each regional population and the associated standard costs required for the delivery of the 'Essential Levels of Care' (Livelli Essenziali di Assistenza). ${ }^{23}$ Such a choice identifies the healthcare system of Emilia-Romagna as an institutionally recognised reference target for the rest of the country. Lastly, the population size, health conditions and socio-economic environment of this area makes it also comparable with a large share of regions and of small-medium sized countries, such as those located in central and northern Europe.

This study bears also some data limitations. First, we did not have information with which to test whether increases in DRG prices translated into changes in other important aspects of hospital performance including clinical outcomes. Moreover, we cannot observe the underlying costs dynamics, and this prevented us from examining whether responses across hospitals depend on the gap between DRG prices and actual costs.

Despite these limitations, our findings can provide potentially relevant indications for health policy and contribute to the international literature that investigates the role of fixed prices as regulatory tools across different healthcare systems. Taken together, the results suggest that DRG tariffs affect the decisions of public hospitals and can be exploited to encourage the delivery of certain treatments. Such effects may vary over time and according to the pre-policy conditions under which hospitals operate, as we find a greater impact in the mediumrun and for providers with a higher unused capacity before policy implementation.

\section{APPENDIX}

Table AI. Falsification test on the sub-sample of non-elective patients

\begin{tabular}{|c|c|c|c|c|}
\hline & \multicolumn{2}{|c|}{$\ln$ (number of inpatient discharges) } & \multicolumn{2}{|c|}{$\ln$ (average length of stay) } \\
\hline & Medical DRGs & Surgical DRGs & Medical DRGs & Surgical DRGs \\
\hline$\Delta \ln (\mathrm{p}) \times($ Pre_policy $)$ & $\begin{array}{c}0.411 \\
(0.245)\end{array}$ & $\begin{array}{c}0.484 \\
(0.311)\end{array}$ & $\begin{array}{r}-0.075 \\
(0.134)\end{array}$ & $\begin{array}{c}0.270 \\
(0.325)\end{array}$ \\
\hline$\Delta \ln (\mathrm{p}) \times($ Short_run $)$ & $\begin{array}{r}-0.336 \\
(0.382)\end{array}$ & $\begin{array}{c}0.259 \\
(0.622)\end{array}$ & $\begin{array}{c}0.137 \\
(0.117)\end{array}$ & $\begin{array}{c}0.034 \\
(0.257)\end{array}$ \\
\hline$\Delta \ln (\mathrm{p}) \times($ Medium_run $)$ & $\begin{array}{r}-0.679 \\
(0.714)\end{array}$ & $\begin{array}{c}-0.047 \\
(1.234)\end{array}$ & $\begin{array}{c}0.445 \\
(0.272)\end{array}$ & $\begin{array}{c}-0.722 \\
(0.438)\end{array}$ \\
\hline Hospital-DRG fixed effects & $\mathrm{Y}$ & $\mathrm{Y}$ & $\mathrm{Y}$ & $\mathrm{Y}$ \\
\hline Year fixed effects & $\mathrm{Y}$ & $\mathrm{Y}$ & $\mathrm{Y}$ & $\mathrm{Y}$ \\
\hline Hospital $\times$ Year fixed effects & $\mathrm{Y}$ & $\mathrm{Y}$ & $\mathrm{Y}$ & $\mathrm{Y}$ \\
\hline DRG trends & $\mathrm{Y}$ & $\mathrm{Y}$ & $\mathrm{Y}$ & $\mathrm{Y}$ \\
\hline Adj. R-squared & 0.907 & 0.860 & 0.702 & 0.724 \\
\hline Obs. & 13328 & 5217 & 13328 & 5217 \\
\hline
\end{tabular}

DRGs, diagnosis-related groups.

Robust standard errors clustered at the hospital level are in parentheses. $* p<0.1 . * * p<0.05$. ***p $<0.01$.

\footnotetext{
${ }^{22}$ A comparison of the risk-adjusted performance measures provided by the National Program for Outcome Assessment (Programma Nazionale Esiti) between Emilia-Romagna and the other centre-north regions is available from the authors upon request. See also Nuti et al. (2016).

${ }^{23}$ The five regions are Lombardy, Veneto, Emilia-Romagna, Umbria and Marche. Emilia-Romagna was included in the group of the three benchmark regions both in 2013 and 2014.
} 


\section{CONFLICT OF INTEREST}

The authors declare that they have no actual or potential conflicts of interest between themselves and others that might bias their work.

\section{ACKNOWLEDGEMENTS}

We are grateful for helpful suggestions received by two anonymous referees, by Rowena Jacobs, Søren Rud Kristensen, Irene Mammi, Davide Raggi and Luigi Siciliani and by the participants at the iHEA World Congress in Dublin, at the AIES Conference in Venice and at a seminar held at the Department of Economics of the University of Bologna. The research was funded by the Health Department of Emilia-Romagna (Italy), and we thank Eugenio Di Ruscio who coordinated the project for the Health Department. The views expressed are those of the authors and not those of the funders. Ethical approval is not required as this type of study is classed as low risk because of minimal burden or intrusion for participants, as it is based on the analysis of pseudonymised routine administrative data.

\section{REFERENCES}

Agenas. 2011. I tempi di attesa nei siti web di Regioni e Aziende sanitarie: la prospettiva del cittadino. Agenzia sanitaria per i servizi sanitari regionali.

Allen P, Keen J, Wright J, Dempster P, Townsend J, Hutchings A, Street A, Verzulli R. 2012. Investigating the governance of autonomous public hospitals in England: multi-site case study of NHS Foundation Trusts. Journal of Health Services Research and Policy 17(2): 94-100.

Allen T, Fichera E, Sutton M. 2016. Can payers use prices to improve quality? Evidence from English hospitals. Health Economics 25: 56-70.

Barros PP, Siciliani L. 2012. Public and private sector interface. In Handbook of Health Economics, Pauly MV, McGuire TG, Barros PP (eds), vol. 2, chapter 15. Elsevier Science BV: Amsterdam; 927-1001.

Berta P, Callea G, Martini G, Vittadini G. 2010. The effects of upcoding, cream skimming and readmissions on the Italian hospitals efficiency: a population-based investigation. Economic Modelling 27: 812-882.

Barbetta GP, Turati G, Zago A. 2007. Behavioral differences between public and private not-for-profit hospitals in the Italian national health service. Health Economics 16: 75-96.

Bloom N, Propper C, Seiler S, van Reenen J. 2015. The impact of competition on management quality: evidence from public hospitals. Review of Economic Studies 82: 457-489.

Bordignon M, Turati G. 2009. Bailing out expectations and public health expenditure. Journal of Health Economics 28: 305-321.

Cappellari L, De Paoli A, Turati G. 2016. Do market incentives in the hospital industry affect subjective health perceptions? Evidence from the Italian PPS-DRG reform. Journal of the Royal Statistical Society, Series A, 179: 885-905.

Chalkley M, Malcomson JM. 2000. Government purchasing of health services. In Handbook of Health Economics, Culyer AJ, Newhouse JP (eds), vol. 1, chapter 15. Elsevier: Amsterdam; 847-890.

Chalkley M, Malcomson JM. 2012. Contracts, information and incentives in health care. In The Elgar Companion to Health Economics, Jones AM (ed.), chapter 22. Edward Elgar: Cheltenham, UK and Northampton, USA; $240-249$.

Charlson ME, Pompei P, Ales KL, McKenzie CR. 1987. A new method of classifying prognostic comorbidity in longitudinal studies: development and validation. Journal of Chronic Disease 40: 373-383.

Clark AE, Milcent C. 2011. Public employment and political pressure: The case of French hospitals. Journal of Health Economics 30: 1103-1112.

Clemens J, Gottlieb J. 2014. Do physicians' financial incentives affect medical treatment and patient health? American Economic Review 104(4): 1320-1349.

Cutler DM. 1995. The incidence of adverse medical outcomes under prospective payment. Econometrica 63: $29-50$.

Dafny LS. 2005. How do hospitals respond to price changes? American Economic Review 95(5): 1525-1547.

Dranove D. 2012. Health care markets, regulators, and certifiers. In Handbook of Health Economics, McGuire T, Pauly M, Barros PP (eds), vol. 2, chapter 10. Elsevier: Amsterdam; 639-690.

Gilman BH. 2000. Hospital response to DRG refinements: the impact of multiple reimbursement incentives on inpatient length of stay. Health Economics 9: 277-294. 
Giuffrida A, Lapecorella F, Pignataro G. 1999. Efficiency of health care production in different hierarchically structured hospitals. CHE Research Paper 14.

He D, Mellor JM. 2012. Hospital volume responses to Medicare's outpatient prospective payment system: evidence from Florida. Health Economics 31: 730-743.

Hodgkin D, Mcguire TG. 1994. Payment levels and hospital response to prospective payment. Journal of Health Economics 13: $1-29$.

Januleviciute J, Askildsen JE, Kaarbøe O, Siciliani L, Sutton M. 2015. How do hospitals respond to price changes? Health Economics 25(5): 620-636.

Liang L. 2015. Do diagnosis-related group-based payments incentivize hospitals to adjust output mix? Health Economics 24(4): 454-469.

Lindrooth R, Bazzoli G, Clement J. 2007. The effect of reimbursement on the intensity of hospital services. Southern Economic Journal 73(3): 575-587.

Marini G, Miraldo M, Jacobs R, Goddard M. 2008. Giving greater financial independence to hospitals - does it make a difference? The case of English NHS Trusts. Health Economics 17: 751-777.

Martini G, Berta P, Mullahy J, Vittadini G. 2014. The effectiveness-efficiency trade-off in health care: the case of hospitals in Lombardy, Italy. Regional Science and Urban Economics 49: 217-231.

Ministry of Health. 2011. "Rapporto Nazionale di monitoraggio dei livelli essenziali di assistenza: Anni 2007-2009". [National report for monitoring the "Essential Levels of Care": Years 2007-2009].

McGuire TG. 2000. Physician agency. In Handbook of Health Economics, Culyer AJ, Newhouse JP (eds), vol. 1, chapter 9. Elsevier: Amsterdam; 461-536.

Newhouse JP. 1989. Do unprofitable patients face access problems? Health Care Financing Review 11(2): 33-42.

Nuti S, Vola F, Bonini A, Vainieri M. 2016. Making governance work in the health care sector: evidence from a "natural experiment" in Italy. Health Economics, Policy, and Law 11(1): 17-38.

OECD. 2013. Health at a glance 2013: OECD indicators, OECD Publishing: Paris.

Seshamani M, Schwartz JS, Volpp KG. 2006. The effect of cuts in Medicare reimbursement on hospital mortality. Health Services Research 41(3 Part I): 683-700.

Stagg V. 2006. CHARLSON: Stata module to calculate Charlson index of comorbidity. (Available from: https://ideas.repec. org/c/boc/bocode/s456719.html) (accessed 30 March 2014).

Verzulli R, Jacobs R, Goddard M. 2011. Do hospitals respond to great autonomy? Evidence from the English NHS. University of York CHE Research Paper 64.

Wu VY, Shen YC. 2014. The long-term impact of medicare payment reductions on patient outcomes. Health Services Research 49(5): 1596-1615. 